\title{
REPRESENTACIONES FEMENINAS EN EL CINE: PODER Y GÉNERO EN LA PELÍCULA ROSARIO TIJERAS
}

\section{FEMALE REPRESENTATION IN THE CINEMA: POWER AND GENDER IN THE FILM ROSARIO TIJERAS}

\author{
Azul Kikey Castelli-Olvera ${ }^{1}$ y Rosa María Valles-Ruiz ${ }^{2}$
}

\begin{abstract}
RESUMEN
En este trabajo se sostiene que la película Rosario Tijeras es un filme que puede considerarse feminista pues, Rosario Tijeras es una mujer empoderada que cuenta su propia historia. Lo anterior en consideración a que el empoderamiento enfocado desde el movimiento feminista y la perspectiva de género implica que las mujeres accedan en igual medida a los bienes materiales, intelectuales e ideológicos que permitan que tomen decisiones sobre sus cuerpos y sus vidas, se entiende que no en todos los casos el empoderamiento se da de manera positiva sino que puede manifestarse como confrontación con la propia estructura social. En este sentido desempeña un papel fundamental el contexto. Rosario Tijeras vive en un contexto definido por hombres, pero durante el desarrollo de la historia va asumiendo decisiones sobre su cuerpo y sobre su vida aún a costa de su propia seguridad, convirtiéndose en una transgresora. El análisis se realiza a partir de: 1. la propuesta de Scott, quien desagrega los elementos que constituyen la identidad de género y que en este trabajo funcionan como categorías; el análisis semiótico partiendo de Cirlot y Tresidder; y 2. El análisis formal a través de la descripción de antecedentes y uso del lenguaje cinematográfico.
\end{abstract}

Palabras clave: cine feminista; empoderamiento; género; semiótica.

\begin{abstract}
This paper argues that the film Rosario Tijeras is a film that can be seen as feminist, Rosario Tijeras is an empowered woman who tells her own story. This considering that the empowerment focused from the feminist movement and gender implies that women's access equally to the material, intellectual and ideological assets out of which to make decisions about their bodies and their lives, it is understood that no in all cases empowerment occurs positively but can manifest as confrontation with the social structure. In this sense it plays a key role context. Rosario Tijeras lives in a context defined by men, but in the course of history is taking decisions about her body and her live at the cost of their own safety, becoming a transgressor. The analysis is based on: 1. the proposal for Scott, who breaks down the elements of gender identity in this work and function as categories; semiotic analysis based on Cirlot and Tresidder; and 2. The formal through the background description and use of film language analysis.
\end{abstract}

Keywords: feminist film; empowerment; gender; semiotics.

Tipología: Artículo de Investigación Científica y Tecnológica

Fecha de recepción: 09/06/2015

Fecha de aceptación: 08/09/2015

Como citar este artículo: Castelli-Olvera, A. \& Valles Ruiz, R. (2015). Representaciones femeninas en el cine: poder y género en la película Rosario Tijeras. Jangwa Pana, 14, 46 - 58.

1. Doctora en Ciencias Sociales. Universidad Autónoma del Estado de Hidalgo, México. Correo: sakuntala83@yahoo.com.mx

2 Doctora en Ciencias Políticas y Sociales. Universidad Autónoma del Estado de Hidalgo, México. Correo: vallezcurdia@gmail.com 


\section{INTRODUCCIÓN}

$\mathrm{E}$ cine, ese medio que Metz (2001) llama técnica de lo imaginario, enclavado en un momento histórico: el capitalismo, y en un estado de la sociedad llamada industrial, convierte la ficción como imagen del deseo en el espejo del yo representado y vivido a través de la pantalla. De este modo el cine enuncia la ficción que relata y al espectador al que apela. Es a través de este acto de enunciación que se hacen presentes categorías como el tiempo, porque a partir del discurso se establecen el antes, el después y sobre todo el ahora, definidas éstas a partir del uso del tiempo que compete al sujeto que habla (Benveniste, 1999).

Esa enunciación entendida como poner en práctica la lengua, en este caso el lenguaje cinematográfico, compuesto por planos, movimientos de cámara, iluminación, música y narrativa, se convierte en un centro de referencia que se apropia del aparato formal del lenguaje y enuncia su posición, en relación simétrica con el espectador, refiriendo un mundo, un contexto correferido en su discurso (Valero, s.f). De este modo el film se convierte en producto histórico de la época en que se produce no por su exactitud histórica, sino porque "... sea como fuere, en todo filme subyace el sustrato psicológico de su creador, que no es más que una proyección subliminal de la mentalidad de la sociedad del momento histórico en que la obra se gestó" (Valero,s.f).

Partiendo de esta perspectiva, en la década de los setentas el movimiento feminista inició los primeros estudios que analizaban la relación de las mujeres y el cine. La perspectiva fue crítica pues se miró al pasado en la búsqueda de los estereotipos reiterados por la industria cinematográfica (Lema, 2003). En su ensayo La imagen de la mujer en el Film, Smith analiza la representación de las mujeres en el cine y la falta de cambio en sus roles. La autora sostiene que en el caso masculino, los hombres asumen múltiples representaciones, pocas veces sexualizadas, mientras que a las mujeres se les representa como atracción física y objeto sexual (Film gender and sexuality, 2014). Así mismo, en 1975, Smith (Montiel, 1992) recupera en su artículo Women who makes movies, la participación de las mujeres como directoras de cine en la historia, llegando a ubicarlas desde 1896. Entre los nombres hallados se pueden mencionar: Mary Pickford, Lilian Gish, Elizabeth Pickett, Ida May, Grace Cunard, Ruth Ann Baldwin, Cleo Madison, Elsie Jane Wilson, Julia Crawford y Dorothy Arzner.

Rosen (2012) fue la primera en explorar la relación entre las mujeres en la pantalla y fuera de ésta en su libro Las Venus de las palomitas: Mujeres, películas y el sueño americano. Mientras que Haskell, en 1974, en su libro De Reverencia a violación: el tratamiento de las mujeres en el cine, hace una crítica desde el feminismo donde expone los cambios en la imagen de la mujer en la pantalla y las razones por las que se han dado esos cambios (Crowdus \& Wallace, 1981).

En 1980, Kunh, en su libro Women's pictures. Feminism and Cinema, recupera la historia reciente del feminismo y los análisis fílmicos. En este trabajo, la autora, además de mencionar a Rosen y Haskell, apunta que para el avance del análisis fílmico feminista contribuyeron: el nacimiento, en 1972, de la revista Women and Film, el primer festival de mujeres y cine en Toronto y la publicación, en 1974, del libro Women and their sexuality in the new film, de Joan Mellen. Kunh expone que en el desarrollo de teoría feminista la contribución fue casi en su totalidad estadounidense, con algo de participación francesa y muy poca española (Montiel, 1992).

El objeto de análisis de la teoría feminista, como lo menciona Kunh (1991), ha sido generalmente el cine hollywoodense. Los análisis exponen las ausencias de las mujeres en los textos fílmicos o señala cómo se construyen las mujeres a través de las imágenes o su estructura narrativa. Esta autora también señala que visibilizar lo invisible también se da mediante la realización de filme "...mediante el examen del lugar que ocupan las 
películas en el contexto en que han sido realizadas, analizando cómo se arman las películas, qué tipos de relaciones sociales están implicados en el proceso, y qué relaciones existen entre los modos de producción y la formación de estructuras y mecanismos textuales puestos de evidencia por la perspectiva feminista”. Kunh reconoce que no todo el cine realizado por mujeres es feminista, $\mathrm{y}$ que pese a que algunas feministas estén en desacuerdo, también los hombres pueden producir cine feminista. Así mismo, si bien el tema central ha sido el cine estadounidense, el cine latinoamericano ha sido motivo de análisis, sobre todo desde los años sesenta y setenta, donde, además de analizar la representación de las mujeres en la pantalla, surgieron directoras de cine que plasmaron su sentir y su impresión de lo femenino en sus films. Entre ellas se puede mencionar a: Margot Benacerraf, María Luisa Bemberg, Fina Torres, Suzana Amaral, María Novaro, Lucrecia Martel y Lucía Puenzo (Torres, 2008).

En consideración a lo anterior, en este trabajo se sostiene que la película Rosario Tijeras (Maillé, 2005) es un film que puede considerarse como feminista pues el personaje principal, Rosario, es una mujer empoderada que cuenta su propia historia determinada por un contexto, determinado por la violencia y el narcotráfico. Lo anterior se sostiene en consideración a que el empoderamiento enfocado desde el movimiento feminista y la perspectiva de género implica que las mujeres accedan en igual medida que el hombre a los bienes materiales, intelectuales e ideológicos que permitan que ellas tomen decisiones sobre sus cuerpos y sobre sus vidas (Kabeer, 1991). Se entiende que no en todos los casos el empoderamiento se da de manera positiva socialmente aceptada, sino que puede manifestarse en conductas antisociales vinculadas estrechamente al contexto en el cual se desenvuelve el personaje. Aunado a esto, la película Rosario Tijeras está basada en la novela homónima de Jorge Ramos Francos considerada por Quattlebaum como literatura feminista pues, según esta autora, las obras de Franco Ramos no siguen la tradición masculina de la literatura hispanoamericana que muestra prevalencia de valores masculinos sino que enclava a personajes femeninos en contextos políticos, sociales y económicos reales que muestran la transformación de los roles femeninos en situaciones determinadas. Así mismo, el personaje de Rosario, pese a desarrollarse y vivir en un contexto definido por hombres, durante el desarrollo de la estructura dramática de la historia va asumiendo decisiones sobre su cuerpo y sobre su vida aun a costa de su propia seguridad, convirtiéndose en una transgresora.

El análisis del film se realiza a partir de: 1. la propuesta de Joan Scott, quien desagrega los elementos que constituyen la identidad de género, $y$ que en este trabajo funcionan como categorías, y el análisis semiótico a partir de Cirlot y Tresidder; y 2. el análisis formal del mismo film a través de la descripción de sus antecedentes y uso del lenguaje cinematográfico.

\section{MATERIALES Y MÉTODOS}

De primera instancia se inició el acercamiento al objeto de estudio realizando un análisis formal del mismo, lo que implica la descripción de los antecedentes del film y el análisis del manejo del lenguaje cinematográfico utilizado como parte de la estructura dramática de la película. Se analizan el uso de los planos, movimientos de cámara, uso de la música, color y juegos temporales que dentro de la estructura dramática de la historia toman sentido.

Además, se puede realizar un acercamiento teórico distinto al análisis de la técnica o la narrativa. Por tal razón, para un exploración más extensa, se eligió un personaje, en este caso Rosario, la joven sicaria de Medellín; se optó por la teoría de género pues es una categoría derivada de los estudios feministas que ayuda a comprender la construcción del deber ser hombre o mujer, según sea el caso y que esta construcción se da dentro de las relaciones de poder de uno y otra (Scott, 1996). 
Como se verá más adelante, Rosario resulta una representación de género controvertida pues en ella se mezclan la ternura con el homicidio, la belleza y la maldad, la inocencia y la perversión, características que se excluyen unas a otras, pero que en esta mujer se mezclan de manera natural. El análisis se realizará en cuatro vertientes cada una determinada por los elementos del género que distingue Scott (1996):

1. Los símbolos y los mitos culturalmente disponibles que evocan representaciones múltiples. Para esta categoría se utiliza el Diccionario de Símbolos de Cirlot (1992) y el Diccionario de Símbolos de Tresidder (2008).

2. Los conceptos normativos que manifiestan las interpretaciones de los significados de los símbolos. Estos conceptos se expresan en doctrinas, religiosas, educativas, científicas, legales y políticas, que afirman categórica y unívocamente los significados de varón y mujer, masculino y femenino.

3. Las instituciones y organizaciones sociales de las relaciones de género: el sistema de parentesco, la familia, el mercado de trabajo segregado por sexos, las instituciones educativas, la política.

4. La identidad. Destacan los análisis individuales -las biografías-, pero también hay posibilidad de tratamientos colectivos que estudien la construcción de la identidad genérica en grupos.

Cada una de las categorías anteriores se aplicó al personaje de Rosario Tijeras, para visibilizar los elementos del género que determinan esta representación femenina y que derivan en empoderamiento, entendiendo que éste asume las características que le permite el contexto. Las categorías que no se encuentren, no se mencionarán en el análisis.

\section{RESULTADOS}

Rosario Tijeras, de novela a película, de película a leyenda, una mujer fuera de serie o de muchas series. Franco Ramos relata la vida de una sicaria de la ciudad de Medellín, Colombia, en los años ochenta. La novela fue muy bien recibida por el público, en Colombia, convirtiéndose el suyo en un récord difícil de superar, ya que tal y como lo menciona el autor: "...sabía que la podía superar literariamente, porque la idea siempre es madurar como escritor, pero superarla en ventas era cosa complicada. Desistí de esa idea, porque también descubrí que en eso de las ventas influye mucho el azar" (García, 2009).

Jorge Franco Ramos nació en Medellín en 1962, estudió dirección y realización de cine en The London International Film School, en Inglaterra. Realizó estudios de Literatura en la Universidad Javeriana. Quedó como finalista y primer lugar en varios concursos de literatura, novela y cuento. Con los premios obtenidos ha publicado las obras ganadoras. Es uno de los escritores más reconocidos de Colombia, separado de la generación y la narrativa de García Márquez, pues su propuesta es diferente. Su narrativa trata de reflejar su patria con toda su problemática, vitalidad y belleza; en sus novelas se mezcla el amor con la sangre y el sacrificio con los asesinatos. Una de las características más recurrentes en su obra son los personajes femeninos como protagónicos; esto se debe a que él considera Medellín como una ciudad de matriarcados pese al alto nivel de machismo existente (Vallejo, 2000). Su novela Rosario Tijeras se considera entre las mejores creaciones literarias de Colombia (Vallejo, 2007).

En este caso nos centraremos únicamente en la novela Rosario Tijeras, que fue adaptada para cine por Emilio Maillé, y estrenada en Colombia en 2005 y en México en 2006. Maillé, de origen mexicano, nació en 1963 y en la actualidad habita en París. Cursó estudios en literatura y cinematografía en la Sorbona en Francia. Nacido mexicano pero educado en Europa, este director está acostumbrado al escándalo y a las causas imposibles. Varias de sus películas (entre ellas Los años Azurra) fueron inspiradas en los sueños fallidos 
de otros. Manolette y Curro fueron de las películas más controvertidas en España, y Maillé tuvo que enfrentar a aficionados al cine y a la fiesta brava para poder presentarlas, sin contar con las trabas puestas por los familiares de sus personajes principales y por los personajes mismos. Tal es el caso de Curro Romero. Enamorado del cine desde pequeño, empezó a trabajar en esta industria de manera formal desde 1990. Ha incursionado principalmente en el género documental siendo Rosario Tijeras su primer largometraje (Riquer, 2013).

Es importante mencionar que la industria cinematográfica colombiana tuvo sus inicios a finales del siglo XIX, sin embargo, no logró el auge esperado porque las políticas del país no favorecieron la existencia de un organismo dedicado a la producción y promoción del cine. De propuestas innovadoras y retadoras hacia al sistema, el cine colombiano pasó por lo que se dio en llamar el cine de pornomiseria, donde directores sin conocimientos reales sobre este arte explotaban imágenes de pobreza y miseria que vendían como la imagen de Colombia. Hace algunos años, el gobierno colombiano promovió el desarrollo de un organismo encargado del llamado séptimo arte con lo cual Colombia ha producido una mayor cantidad de films de calidad entre ellos María llena eres de gracia y Rosario Tijeras (Cine Colombia, 2010).

\section{Análisis Formal}

Rosario Tijeras es la historia de una joven sicaria que habita en la ciudad de Medellín, capital de Antioquia y segunda ciudad más importante de Colombia, cuna de los "paisas", grupo de personas muy apegadas a lo tradicional en cuestiones familiares. La ciudad se ve atravesada por la industria y la inversión extranjera desde principios del siglo XX. Reconocida en la industria textil, cafetalera y minera, esta ciudad es también uno de los centros de medicina más avanzados de Latinoamérica. Asociada al narcotráfico, recuerda al Chicago de los años treinta; Medellín fue asolada por una ola de violencia que toca las últimas décadas, violencia que alcanzó su punto más alto en los ochenta, cuando estuvo controlada por el cártel de Medellín (Colombia Link, 2010). Pablo Escobar controlaba las organizaciones criminales del narcotráfico y había declarado la guerra al Estado colombiano dando como resultado una exacerbación de la violencia durante el periodo de 1984 a 1993 (Biografías y vidas, 2014). El autor ambienta en 1989 la historia de Rosario Tijeras, por lo que se encuentra ubicada justo en medio del "gobierno" de este cártel.

La realización resultó de una coproducción mexicana, española, colombiana y brasileña, y fue estrenada en 2005 en Colombia y en 2006 en México. La cinta aborda temáticas como violación, narcotráfico y corrupción, temas que se mezclan en la vida de Rosario, la joven sicaria y prostituta de la que se enamoran Emilio y Antonio. Llena de sucesos violentos, la historia de Rosario es contada llena de simbolismos religiosos que rayan en el fanatismo y que forman parte de la subcultura sicaria que este film trata de reconstruir.

Rosario Tijeras significa un triunfo para el cine colombiano con todo y carencias narrativas, pues a pesar de las trabas se ha logrado consolidar, y Colombia ingresa con más ímpetu a la industria cinematográfica gracias a la creación de un organismo gubernamental se aprecia la permanencia de la línea trabajada tanto por el escritor como por el director y el cine colombiano mismo: el gusto por los temas de escándalo, por la crítica y por Medellín, ciudad de droga, corrupción, muerte y pecado, pero también de vida, de sueños y esperanza, ciudad amada por el escritor a pesar de sus defectos. Rosario es una mujer que pertenece a la ficción de la novela y a los sueños del escritor, pero tal vez encarne la vida de muchas mujeres no sólo colombianas, el mismo Franco Ramos acepta que para la creación del personaje se inspiró en "una tesis de la Facultad de Psicología de la Universidad de Antioquia, que trataba el tema de la religiosidad y el sicariato", de donde recu- 
pera uno de los testimonios de las niñas metidas como sicarias (Skar, 2007).

Contada a través de saltos temporales (flashback), vemos a Antonio sentado en la sala de un hospital en espera de noticias de Rosario, el reloj en la pared se convierte en punto de fuga que traslada al espectador al antro el "Acuario", dentro de este flash back se encuentran otros más que permiten que el filme narre la niñez y juventud de Rosario y las experiencias que la marcaron y la convirtieron en sicaria. El uso de saltos temporales es vertiginoso con lo que el director logra transmitir el ritmo alocado de vida en el que se desenvuelve la joven.

El uso de la música es diegético en las primeras y últimas escenas pues los personajes se encuentran dentro de un antro donde múltiples parejas bailan al ritmo de una música cadenciosa y sensual que será el marco perfecto para la aparición de Rosario, y se convertirá en tema representativo del personaje. El uso extradiegético se ve vinculado con la carga dramática de la historia y contribuye a resaltar los momentos de tensión dentro del filme.

En cuanto al uso de los planos son recurrentes los planos medios o medium close up que permiten resaltar gestos y diálogos de los personajes. También los primerísimos planos (close up, big close up), sobre todo para poner énfasis en el uso de drogas, heridas y rasgos del rostro, de este modo tenemos acercamiento a los labios rojos de Rosario, labios que además de ser hermosos son su principal arma, pues ella mata después de besar. El cañón de la pistola también se convierte en protagónico: Entre besos y balas la protagonista se va sobreponiendo a la situación de indefensión en la cual la deja su contexto y su familia.

Los planos generales ubican al espectador en distintos espacios, desde el hogar de Antonio y el de Rosario, la discoteca, la ciudad de Medellín. Mientras que los planos enteros (full shot) se utilizan para resaltar la belleza, el cuerpo, la vesti- menta de los personajes, así mismo este tipo de planos es usual en las escenas de sexo donde se utilizan para resaltar el placer, el deseo y el gozo que vive el personaje de Rosario; si bien, hay escenas implícitas donde se asume que Rosario es prostituida, pero las escenas de sexo explícitas son de Rosario ejerciendo su sexualidad libremente, con la pareja que desea y disfrutando su cuerpo.

\section{Análisis semiótico y de género}

Este es un campo ampliamente retomado en la película. La subcultura sicaria a la que pertenece Rosario es sumamente católica, sólo que las peticiones varían, el concepto que se tiene sobre el asesinato, el robo o el tráfico de drogas está más relacionado con la sobrevivencia que con la delincuencia; por lo tanto, se considera que se tiene derecho a la protección divina, los sicarios piden cosas, como "ayúdame a matarlo", "que no me vayan a agarrar", etc., y en esta soledad se crea un amplio fanatismo, se recurre a diversos santos del catolicismo, pero sobre todo a la Virgen, incluso las balas se bendicen para que lleguen a la víctima de manera certera.

Rosario es creyente devota de la Virgen, cuya figura tiene dos vertientes, la religiosa y la materna (de la primera se hablará en este apartado, la segunda se analizará posteriormente), ella bendice a su hermano y le regala sinfín de escapularios que tienen diversas funciones. Para esta mujer, su hermano muere debido a que olvida su amuleto y antes de matar al asesino de su hermano, Rosario pide la ayuda de la Virgen, pide su protección apelando a su carácter de madre universal, ese cariño que la protagonista no encontró en su hogar.

Es en este ambiente de violencia y religión en el que se mueve la protagonista de este film. La fe le da un sentimiento de protección que no sólo la alcanza a ella sino a todos los que la rodean, es esa fe la que le da valor, pero también la que la pierde. La muerte es un paso y, por lo tanto, 
la creencia de una existencia después de ella el amor, el perdón y el apoyo de un Dios se entrelaza con la vida en la cual hay que disfrutar como dice Rosario "Nunca hay que irse sin hacer lo que te gusta".

\section{Educación}

A diferencia de la religión este aspecto se maneja de manera más velada, únicamente se habla de él cuando Emilio invita a Rosario a cenar con su padres, ella descubre que él ha inventado que ella estudia diseño gráfico y que su padre es un importante abogado. Es entonces cuando se revela la educación como bien simbólico del cual Rosario carece, y que a los ojos de los padres de Emilio, de éste y de la "sociedad" hacen de Rosario una mujer con poco valor, pues además de no poseer educación alguna, tampoco hay un varón exitoso como cabeza de la familia de Rosario, elementos todos necesarios para alcanzar el status de Emilio, joven que por otro lado, al parecer cuenta con una esmerada educación, la cual únicamente se supone por el número de personas que asisten al velorio y que se acercan al cuerpo para acariciarlo o despedirse, pero nunca se aclara y tampoco se demuestra en el comportamiento de éste. En este caso la educación se aborda como un bien simbólico de status.

\section{Estructuras de poder: legalidad}

La manera en que tanto Rosario como sus acompañantes actúan hace pensar que no existe límite entre lo legal y lo ilegal. O más bien, la legalidad se presenta de manera distinta a la pensada, no se muestra la legalidad oficial sino una regulación interna al margen de lo legal, pues en el grupo sicario en el que Rosario se encuentra envuelta, las reglas son bien claras y se ven demarcadas incluso por el espacio, en el "Acuario" el antro donde se conocen Rosario, Emilio y Antonio, el espacio de arriba pertenece a la mafia de "Los duros" y las mujeres que están ahí también, la obediencia y la lealtad son reglas importantes en estos grupos. En cuanto a una figura de legalidad oficial únicamente encontramos al juez que es jefe de Rosario, y que ésta asesina, como figura de la legalidad corrupta. La corrupción del contexto legal en el film se relaciona con la vinculación de gobierno y narcotráfico, que en 1989, año de ambientación de la película, se dio como resultado del auge del cártel de Medellín.

\section{Política}

Aunque no se menciona un uso político, es claro que las mujeres como Rosario son utilizadas de manera que sirven para entretener o para asesinar a aquellos que interesan o estorban a la mafia de "Los duros" o a los aliados de éstos, considerando que dentro del cártel de Medellín participaron políticos y altos personajes del gobierno colombiano y estadounidense, el uso político de las mujeres era parte del contexto. En la película vemos este uso de manera concreta en un flash back donde Rosario recuerda su relación con un hombre apodado el "Gringo". uno de los jefes de "Los Duros" se acerca a la protagonista y le señala al hombre apodado así, ella sonríe y le pregunta cuándo y cómo quieren que lo asesine, el jefe le contesta "no has entendido, el "Gringo" es importante para nosotros y preguntó por ti, así que trátalo bien". Más adelante, se presentan una serie de escenas donde se deduce que Rosario vivió con el "Gringo", relación que le resultaba tan desagradable que pasa todo el tiempo drogada, incluso se presenta un flash forward donde ella imagina asesinarlo con un cuchillo, cosa que no ocurre pues el personaje masculino es de suma importancia para el grupo de narcotraficantes $y$, en ese momento, Rosario no está dispuesta a enfrentarlos.

\section{Las instituciones y organizaciones sociales: el sistema de parentesco}

Debido a que los lazos familiares son muy importantes dentro de la subcultura sicaria de Rosario, en la película se nos deja entrever claramente el 
sistema de parentesco, pero únicamente nuclear, esto a través de diálogos y flash back. Quien se presenta con mayor frecuencia es Jonh F., hermano de Rosario con quien ésta entabla diálogos $\mathrm{y}$ con quien vive. Mientras que la figura materna sólo aparece durante el velorio de Jonh F., y posteriormente visitando la tumba del mismo. Se sabe que la familia de esta mujer está conformada por la madre, el hermano y el padrastro, aunque en el velorio del hermano se presuponen otros familiares. También es importante mencionar que los lazos de amistad que se establecen dentro de la mafia resultan tan estrechos como los familiares. Por ejemplo: en la parranda que se organiza para Jonh F. los hombres que acompañan a Rosario se consideran como hermanos del muerto, sólo los más confiables y cercanos, por ello, ella invita a Antonio, con quien ha mantenido largas conversaciones telefónicas y en quien confía ciegamente.

\section{La familia}

La madre: es costurera de profesión, habla de un pasado de lucha por la sobrevivencia y bienestar de sus hijos. En la película se presenta posesiva, frustrada y celosa de Rosario, lo que se observa de manera concreta durante el velorio de Jonh F., donde la madre recibe a Rosario retándola y culpándola de la muerte de su hijo, más adelante, las razones por las que existe esta rivalidad y desprecio se van develando. De este modo, en la escena donde madre e hija se encuentran frente a la tumba de Jonh F. y la madre le reclama a Rosario todo el esfuerzo que hizo para que ella saliera adelante. En el diálogo, le dice "desde chiquita te gustó coger la calle", Rosario le echa en cara entonces el abuso que sufrió cuando niña, ya que fue violada por su padrastro. Su madre contesta "...pero te quedó gustando" Rosario la enfrenta y contesta: "al que le quedó gustando fue a él y usted nunca me lo pudo perdonar", la madre la golpea e insulta llamándola: "respétame, zorra, hija de puta, que yo soy tu madre":
El hermano, cariñoso en ocasiones con Rosario, parece quererla a su manera, pero como la misma Rosario dice: "también él la jode", es decir, la utiliza. Después de que Rosario castra a su agresor, su madre la echa de la casa. A ella no le queda más que irse a vivir con su hermano, quien la presenta con "Los Duros" para que la inicien en la prostitución. Sicario y drogadicto desde muy joven, fanático religioso es asesinado en uno de sus trabajos.

\section{El mercado de trabajo}

Rosario sale huyendo de su casa y se refugia con su hermano quien la introduce en el único mercado de trabajo que conoce para su hermana: la prostitución y el narcotráfico. Si el modo en que la protagonista va escalando peldaños hasta convertirse en sicaria no queda claro en la película, pero parece implícito que se inicia como prostituta y debido a que por su belleza llama la atención de importantes narcotraficantes, empiezan a solicitarle homicidios.

\section{La identidad: las biografías}

Rosario nació en una familia pobre de Medellín, Colombia, hija de una costurera, se desconoce la identidad del padre pero se aprecia la existencia de un padrastro que suele abusar de ella, la madre parece saber de ello, de manera muy disimulada se entiende esto en una escena donde están cenando los tres la madre, Rosario y el padrastro, la madre se despide diciéndole a él "ya me voy a acostar, ahí se queda Rosario por si algo se te ofrece", la madre sale de escena y el hombre mira sonriente a la niña mientras rompe la yema de un huevo estrellado con los dedos (acción que se interpreta como metáfora de abuso sexual), la niña lo observa temerosa.

Años más tarde, Rosario es violada nuevamente por un vecino, esta vez la agresión no quedaría impune, la joven seduce al agresor quien no la 
reconoce y creyendo gustarle la acompaña a su casa, lugar en donde Rosario lo capa con unas tijeras, (de ahí su apodo), la madre en vez de apoyarla, la echa a la calle. Utilizada como objeto sexual desde pequeña, Rosario se inicia en la prostitución a instancias de su hermano, la droga se vuelve parte de su existencia como símbolo de dinero, placer y olvido. Lo mismo sucederá con el sexo que se convierte en un mecanismo de evasión y disfrute corporal que le permite escapar del "mundo de los Duros", pues ella elige a sus amantes, en este caso a Emilio.

A través de estas experiencias se va construyendo la mujer adulta que se nos presenta en el film, Rosario desconfía, no ama más que a su hermano. Hay que considerar que en el mundo de esta mujer, la violencia, el sexo y la droga es el cotidiano, ella nunca recrimina a su hermano el que la haya ofrecido al grupo de narcos, porque asume que era la única opción para sobrevivir y acceder a recursos económicos; para Rosario, su hermano fue el único que estuvo ahí para ella y que la ayudó. Ella obedece sin importar cuál sea el trabajo, aunque prefiere el asesinato a la prostitución. Educada en un ambiente de violencia, ella sabe cómo ganarse el respeto de los demás aunque sea a punta de bala. Mujer aguerrida y solitaria consciente del poder de su belleza, de su fragilidad y de su fuerza, trata de construirse y de ser y al tratar de ganar el derecho sobre sí se niega el derecho a cualquier debilidad, se niega el derecho a amar, a confiar y creer, porque en el mundo en el que se desenvuelve el confiar en alguien puede costarle la vida. Lucha por salir del círculo vicioso en el que se encuentra a través de Emilio y luego de Antonio, finalmente no puede escapar a esa necesidad falsa en donde se hace creer a las mujeres que necesitan de un hombre para salir adelante: "Emilio dijo que me seguiría hasta el infierno, nunca entendió que lo que yo quería era seguirlo a él al cielo".

Muere asesinada víctima de un antiguo enamorado, traicionada como tantas otras veces ella traicionó.

\section{Los símbolos y los mitos: múltiples representaciones}

La imagen de Rosario está rodeada de símbolos y mitos, desde su mismo nombre, el rosario católico significa jardín de rosas, el nombre dado por los místicos cristianos del siglo XIII a una secuencia de oraciones, contadas por una sarta de abalorios y dirigidas a la Virgen María como la Rosa del Cielo, en la superstición se cree que el rosario tiene poder de talismán, en ese sentido Rosario es símbolo femenino ambivalente la mujer que personifica todos los vicios y todas las virtudes (Tresidder, 2008). Un símbolo de femenino, una "corona de rosas" ofrecida a la Virgen, mancillada en un contexto de violencia y narcotráfico. Esto se vincula con su extrema devoción, ella se considera con el poder de bendecir "talismanes", en este caso, escapularios y balas, su fe total le da valor en medio del "infierno" en el que vive.

Si ojos tienen que no me vean, si manos tienen que no me agarren, si pies tienen que no me alcancen, no permitas que me sorprendan por la espalda, no permitas que mi muerte sea violenta, no permitas que mi sangre se derrame, Tú que todo lo conoces, sabes de mis pecados, pero también sabes de mi fe, no me desampares, Amén. (Ramos, 2000, p. 5)

Rosario no tiene apellido, no es nadie y es todas, no hay una identidad legal que le otorgue derechos o que la vincule a una familia, es solo Rosario, una "rosa" de tantas cuya identidad se pierde en las comunas de Medellín, en medio del abuso y el tráfico. El apodo "Tijeras" le viene bien con el nombre ya que simboliza no sólo el arma con la que castró a uno de sus agresores, sino que también representa la cruz de su profunda religiosidad, así como un atributo de las moiras, míticas hilanderas griegas que cortaban con unas tijeras el hilo de la vida de los morta- 
les, así las tijeras son un símbolo ambivalente de creación y destrucción y sobre todo de destino (Cirlot, 1992). De este modo se aprecia cierta construcción de divinidad en el personaje a través de su vínculo con la Virgen María y con el símbolo de destino, quien conoce a esta mujer encuentra su sino, sea de amor o muerte.

Encontramos en Rosario el complejo de Electra (Lagache, 1983), pues se encuentra enamorada de su hermano, figura que representa para ella la protección y el amor paterno. De amante pasa a madre cuando reza por el bienestar de "su niño" y le pide a la virgen que se lo cuide, la imagen religiosa sostiene en sus brazos un niño, Jonh F. es hijo, hermano, padre y amante de Rosario "era mi amor" le dice ella a Antonio "el único que me amaba".

Otro elemento simbólico de gran importancia es la boca y la apariencia de Rosario, con respecto a la primera en el Antiguo Testamento se asociaba la boca con el fuego en este sentido, el significado de este símbolo también es ambivalente porque pues el fuego es creador y destructor o devorador, en este caso, la boca roja de Rosario simboliza el placer y la muerte, ella mata después de besar. Siguiendo esta idea, la apariencia de Rosario, el color de piel, la ropa, las actitudes también se relacionan con el símbolo de la mujer que en la esfera antropológica aparece esencialmente en tres aspectos: como sirena, lamia o ser monstruoso, que encanta o divierte y aleja de la evolución; como madre y como doncella desconocida, Rosario asume los tres papeles en esta historia, es ella misma representación del conocimiento y al mismo tiempo del pecado (Cirlot, 1992).

La carencia de poder de la que hablan muchos grupos feministas es para Rosario una humillación, el no poder decidir sobre su vida o su cuerpo la enfurece y ella se empodera usando como falo simbólico (Lagache, 1983) una pistola, las armas son consideradas como símbolos ambivalentes de poder, en el mundo antiguo, donde la vida era incierta, pocas armas se consideraban destructoras, por ello, muchas veces se conver- tían en símbolo de verdad y justicia (Tresidder, 2008). En el mundo de Rosario el uso de un arma es la posibilidad de acceso al poder, al respeto, a la venganza y a la libertad, debido a que cuando quiere que alguien haga algo, deje de hacerlo, da la orden mientras empuña su pistola y encañona al individuo. Este objeto la hace poderosa y libre, en cierta forma. En este sentido se asume que el personaje de Rosario representa una mujer empoderada entendiendo que en el proceso de empoderamiento, el contexto es determinante. Ella se empodera como puede con las herramientas que tiene, hay que considerar que representa no sólo un género sino una clase social. Es una niña que proviene de una comuna en pobreza extrema, sin educación, sin redes sociales o familiares, inserta en medio de la lucha entre el gobierno y el narcotráfico. Representa una realidad dolorosa y una división de clases sociales clara y brutal, cosa que se observa sobre todo en el encuentro entre la familia de Emilio y de ella, él es y tiene todo lo que ella no tiene, no sólo por ser mujer sino por ser pobre y marginada.

El empoderamiento de Rosario es un empoderamiento que sigue los cánones masculinos basados en el ejercicio del poder ejerciendo la violencia hacia otros y hacia sí mismos (Kaufmann, 2009), y las estrategias usadas en el mundo patriarcal en el que se mueve, pero es empoderamiento al fin y al cabo, lo que le permite sobrevivir, disfrutar de su cuerpo, en un contexto donde no se le da ninguna otra opción.

\section{DISCUSIÓN}

El vestuario de Rosario, su maquillaje y la manera en que se mueve y habla tiene que ver con el estereotipo de prostituta, la ropa corta y pequeña deja ver la belleza de su cuerpo, el cual ella utiliza como herramienta de trabajo y de placer, es como una planta carnívora que espera paciente. Finalmente ella es el símbolo del erotismo y la sexualidad, pero no es objeto sino sujeto capaz de disfrutar su cuerpo y su placer. 
Es la beata más fiel, supersticiosa y fanática, acompañada de velas, santos y escapularios. Es la representación perfecta de Lilith, la primera mujer antes que Eva, la que quiere los mismos derechos de Adán y que por ello es arrojada del Paraíso, la morena candente en contra de la rubia angelical que vemos representada en las cartas del tarot. La piel morena, los labios rojos, el pelo negro son símbolo de pecado (Cirlot, 1992) y contrapunto de diversos cánones occidentales de belleza que encuentran en la blancura de la piel la castidad. Es también la Eva que incita a comer la manzana prohibida, en este caso la droga, la que envenena con un beso. Es Judith la que primero seduce y luego asesina. Un súcubo, el demonio femenino que tanto temían los hombres santos en la edad media, el símbolo de sexo y el placer en su máxima expresión. Es Khali la diosa hindú de la fecundidad y la venganza, el que se la hace se la paga, aunque en ello se juegue la vida. Un mito en sí misma "dicen que eres hombre" le dice Antonio a Rosario como para explicar lo aguerrido de esta mujer "y que cobras un millón por un muerto y un millón cien por un polvo", "es que amar es más difícil que matar" le contesta ella. Rosario es una transgresora en todos los ámbitos, pues en lugar de resignarse a su destino de mujer, como objeto al servicio de los otros, lucha y trata de imponerse a él, se le niega el poder, ella lo arrebata, aunque igual que en el caso de otros personajes femeninos, el contexto, la ciudad, Los duros, etc., terminan por consumirla pero no por domesticarla, ella lucha por ser una mujer, no una conejita de play boy o una doméstica como diría Gayle Rubín (1996).

Si bien no logra romper con estereotipos físicos, ni superar su propio contexto, el personaje de Franco Ramos recreados por Maillé, no es la misma representación de mujeres de antaño, víctimas sufridas en pro de ganarse el cielo o a resignarse a la soledad y el señalamiento social o hasta al silencio, no es la Bugambilia o la María Candelaria del Indio Fernández o la Santa de Federico Gamboa que termina por suicidarse, es una mujer fuerte, valiente pero determinada por su contexto, del cual no tiene salida; es una transgresora y por ello se puede considerar esta película como feminista, puesto que rompe con los roles de género tradicionalmente asignados a las mujeres, convirtiendo a la protagonista en sujeto activo.

Esta lectura del personaje no pretende validar las estrategias de empoderamiento masculino fincadas en la violencia, sino visibilizar la ruptura en la representación de estereotipos femeninos débiles y frágiles, incapaces de ser malas o de defenderse, desvinculadas de sus contextos históricos. Rosario Tijeras representa el poder y la historia, representa su país y una época determinada, representa a una mujer y a todas las mujeres en situaciones similares, "esta relación define a la literatura feminista colombiana como parte de la heterogeneidad latinoamericana que ha permitido explorar un imaginario del mestizaje en el que la mujer es representada con gran poder y autonomía muy diferente a la imagen de la mujer del pasado" (Quattlebaum, 2010).

Lo anterior es sólo un análisis somero, pues a pesar de las carencias que de manera técnica y narrativa tiene esta película, es un objeto de estudio que permite amplios acercamientos teóricos. Representa un logro para el cine colombiano y para el director mismo pues a pesar de ser un consumado cineasta es este su primer largometraje. El manejo de la historia rompe con lo lineal y paga el precio por ello con la fractura de la lógica de la historia y con esos huecos narrativos que tanto se le criticó a este film.

Fuera del ámbito del cine, el personaje de Rosario Tijeras es exquisito, producto de la multiculturalidad de visiones de sus creadores, escapa a esas voces para crear su propia voz, ella es capaz de responder a la pregunta que Freud se planteara al final de su vida y que Marcela Lagarde retoma en uno de sus artículos ¿Qué quieren las mujeres? Rosario responde con tres sílabas: "res-pe-to". Respeto a sus decisiones, a su cuerpo, a sus derechos, a sus virtudes, a sus defectos y capacidades. 


\section{REFERENCIAS BIBLIOGRÁFICAS}

Benveniste, E. (1999). Problemas de lingüística general II. Madrid: Siglo veintiuno editores.

Biografías y vida. (2014). Pablo Escobar. México: Enciclopedia biográfica. Recuperado de: http:// www.biografiasyvidas.com/biografia/e/escobar_pablo.htm

Cine Colombia. (2010). Historia. Colombia. Recuperado de: http://cine.colombia.com/historia/historia.aspx

Cirlot, J. (1992). Diccionario de Símbolos. España: Ciruela.

Colombia Link. (2010). Medellín. Colombia. Recuperado de: http://www.colombialink. com/01_INDEX/index_turismo/destinos/medellin.html

Crowdus, G. \& Wallace, M. (1981). "Film Criticism and Feminism: An Interview with Molly Haskell" en Cinéaste,11, (3), 2-10. Recuperado de: http://www.jstor.org/ stable/41692478

Film, Gender and sexuality (2014) Female confinement in films. A discussion on Sharon Smith's article "the image of women in film". Word Press. Recuperado de: https://blurbetweenthelinesofliminality.wordpress.com/2014/02/20/female-confinement-in-films-a-discussion-on-sharon-smiths-article-the-image-of-women-in-film/

García, L. (2009). Jorge Franco Ramos, la violencia, un tema inevitable. Otro lunes, (3), 42-43. Recuperado de: http://otrolunes.com/ archivos $/ 07 / \mathrm{html} / \mathrm{pdf} / 07 / \mathrm{REVISTA} \% 20$ OTROLUNES\%20NUMERO\%207.pdf

Kabeer, N. (1991). Género, desarrollo y capacitación: Aumentar la concienciación en el proceso de planificación. Development in Practice,1(3), 18-27.

Kaufman, M. (2009). Las siete P's de la violencia de los hombres. Canadá: Save the Children. Recuperado de: http://www.michaelkaufman. com/wp-content/uploads/2009/01/kaufmanlas-siete-ps-de-la-violencia-de-los-hombresspanish.pdf

Kuhn, A. (1991). Cine de mujeres: Feminismo y cine. Madrid. Cátedra: Signo e imagen.
Lagache,D.(1983). Diccionario de Psicoanálisis. Barcelona: Editorial Labor.

Lema, E. (2003). Los modelos de género masculino y femenino En el cine de Hollywood, 1990-2000. Madrid: Universidad Complutense de Madrid.

Maillé, E. (Dirección). (2005). Rosario Tijeras [Película].

Metz, C. (2001) El significante imaginario. Psicoanálisis y cine. Barcelona: Paidós.

Montiel, A. (1992) Teorías del cine. El reino de las sombras. Barcelona: Montesinos editor.

Quattlebaum, A. (2010) El mundo femenino en la obras de Jorge Ramos Franco. Alabama. Auburn University.

Ramos, F. (2000) Rosario Tijeras. Colombia: Literatura Random House.

Riquer, S. (2013) "Las "Miradas múltiples", en ojos de Emilio Maillé" Cine Toma. Revista Mexicana de Cine. Recuperado de 2008 de: http://www.articlearchives.com/1607011-1.html. Rosen, M. (2012) Biografía. Estados Unidos: Marjorie Rosen Site. Recuperado de: http:// www.marjorierosen.com/bio.html

Rubin G. (1996). El tráfico de mujeres: notas sobre la economía política del sexo. Nueva Antropología, VIII (30). México: Universidad Nacional Autónoma de México.

Scott, J. (1996). El género una categoría útil para el análisis histórico. En Marta Lamas. El género: la construcción cultural de la diferencia sexual. Nueva Antropología, Vol. VIII, núm. 30, México, Programa Universitario de Estudios de Género.

Torres, P. (2008) Una historia de conquistas y victorias en el cine latinoamericano: Nueva sociedad. Democracia y política en América Latina. Recuperado de: http://nuso.org/articulo/una-historia-de-conquistas-y-victorias-enel-cine-latinoamericano/

Skar, S. (2007) "Narcotraffic and women in internacional Colombian film: Rosario Tijeras and María llena eres de gracia", ALPHA, (25), 115-131.

Tresidder, J. (2008). Diccionario de los símbolos. México: Tomo. 
Valero, T. (S.F) Cine e historia: más allá de la narración. El cine como materia auxiliar de la historia. Barcelona: Centre d'investigacions film-història, Universidad de Barcelona. Recuperado de: http://www.cinehistoria.com/ cine_e_historia.pdf
Vallejo, O. (2007) "Jorge Franco, el escritor". Otro lunes. 5(16). Recuperado de: http://otrolunes.com/archivos/16-20/?hemeroteca/numero-16/sumario/unos-escriben/jorge-franco-ramos/otras-opiniones/olga-vallejo.html 